\title{
Autoinflammation-PLCG2-associated antibody deficiency-immune dysregulation
}

INSERM

\section{Source}

INSERM. (1999). Orphanet: an online rare disease and orphan drug data base. Autoinflammation-PLCG2-associated antibody deficiency-immune dysregulation. ORPHA:324530

Autoinflammation-PLCG2-associated antibody deficiency-immune dysregulation is a mixed autoinflammatory and autoimmune syndrome disorder characterized by recurrent neutrophilic blistering skin lesions, arthralgia, ocular inflammation, inflammatory bowel disease, absence of autoantibodies, and mild immunodeficiency manifested by recurrent sinopulmonary infections and deficiency of circulating antibodies. Inflammatory phenotype is not provoked by cold temperatures. 